\title{
Addison's Disease, Idiopathic Intracranial Hypertension and Empty Sella - In a 40-Year-Old Woman
}

\author{
MAJ CHOWDHURY ${ }^{\mathrm{a}}$, U SALMA ${ }^{\mathrm{b}}$, QMU AHMED ${ }^{\mathrm{c}}$, M FARIDUDDIN $^{\mathrm{d}}$, A ALAM $^{\mathrm{e}}$, SIMKN KHAN ${ }^{\mathrm{f}}$
}

\begin{abstract}
Summary:
A 40-year-old woman having normal menstrual history got admitted into Bangabandhu Sheikh Mujib Medical University (BSMMU) because of vomiting for previous two months, with a background history of irregular steroid intake for her bodyache for about six years. She was gaining weight and gradually losing vision in her right eye and noticed increased body pigmentation. Physical examination

\section{Introduction:}

Idiopathic intracranial hypertension (IIH) can rarely be associated with an underlying endocrine disorder such as Addison's disease ${ }^{1}$, Cushing's syndrome, hyperthyroidism, hypoparathyroidism or with administration of thyroxin or growth hormone. Though cases of IIH associated with Addison's disease have been in reported in children, there are very few documented case reports of this association in adults ${ }^{2}$, 3 . We describe a case of an adrenal insufficiency associated with IIH leading to empty sella in a 40year-old female.
\end{abstract}

\section{Case Presentation}

A 40-year-old woman with a normal menstrual history was admitted to BSMMU because of vomiting for

1. Dr. M A Jalil Chowdhury, FCPS, MD, Professor of Medicine

2. Dr. Umma Salma, MBBS, FCPS Part II course student

3. Dr. Quazi Mamtaz Uddin Ahmed, FCPS, Assistant Professor of Medicine

4. Dr. Md. Fariduddin, MD, Associate Professor of Endocrinology

5. Dr. Afroza Alam, FCPS, Resident Physician (Asst. Professor of Medicine)

6. Dr. SIM Khairun Nabi Khan, MS, Assistant Professor of Neurosurgery

Bangabandhu Sheikh Mujib Medical University (BSMMU), Dhaka

Address of Correspondence: Prof. M A Jalil Chowdhury, Department of Medicine, Bangabandhu Sheikh Mujib Medical University, Cell Phone: 01819211858, E-mail: majchw@yahoo.com Received: 8 November, 2010

Accepted: 20 September, 2011 revealed BMI $29 \mathrm{~kg} / \mathrm{m}^{2}$, generalized pigmentation more marked in palmar crease and oral mucosa, secondary optic atrophy in right eye and papilloedema in left eye. After biochemical and radiological investigation she was diagnosed as a case of Addison's disease with idiopathic intracranial hypertension (IIH) with empty sella.

(J Bangladesh Coll Phys Surg 2012; 30: 53-55)

previous two months. She was taking tablet predisolone 5mg irregularly about 6 years for her bodyache. She was gaining weight and at the same time noticed increased body pigmentation. She was also gradually losing vision in right eye. She had no history of postpartum hemorrhage. On examination she was conscious, obese (BMI $29 \mathrm{~kg} / \mathrm{m}^{2}$ ), afebrile and her blood pressure was 100/70 mmHg with no postural drop. She had generalized pigmentation including pigmentation of her palmer crease (Fig 1) and oral mucosa. Opthalmoscopy revealed secondary optic atrophy in right eye and papillodema in left eye. No focal sign was found on neurological examination. All her secondary sex characteristics were normal. Initial biochemical analysis revealed serum sodium $130 \mathrm{mmol} / \mathrm{L}$, serum potassium $4.1 \mathrm{mmol} / \mathrm{L}$, serum creatinine $1.2 \mathrm{mg} / \mathrm{dl}$, plasma random glucose 5.9 $\mathrm{mmol} / \mathrm{L}$, normal complete blood count with normal PBF, ESR $40 \mathrm{~mm}$ in first hour. MRI of brain demonstrated empty sella (Fig 2). Lumbar puncture performed in lateral decubitus position revealed CSF pressure of $200 \mathrm{~mm}$ of water. CSF analysis showed WBCs $4 / \mathrm{mm}^{3}$, RBC nil, organism nil, protein $0.3 \mathrm{~g} / \mathrm{L}$ and glucose $3.5 \mathrm{mmol} / \mathrm{L}$. MT was $5 \mathrm{~mm}$, $\mathrm{x}$-ray chest normal, and abdominal ultrasound including adrenal glands revealed no abnormality. Her baseline endocrine test is seen in Table 1. 


\section{Table-I}

Baseline endocrine test reports

\begin{tabular}{lcc} 
Test & Result & Comment \\
\hline ACTH & $207.0 \mathrm{pg} / \mathrm{ml}$ & high \\
Serum Cortisol & $25.5 \mathrm{nmol} / \mathrm{L}$ & low \\
LH & $39.02 \mathrm{IU} / \mathrm{L}$ & normal \\
FSH & $19.43 \mathrm{IU} / \mathrm{L}$ & normal \\
Prolactin & $14.90 \mathrm{ng} / \mathrm{ml}$ & normal \\
TSH & $1.49 \mathrm{mIU} / \mathrm{L}$ & normal \\
FT4 & $11.20 \mathrm{pmol} / \mathrm{L}$ & normal \\
\hline
\end{tabular}

Initially she was put on oral hydrocortisone 30mg, ondensetrone $24 \mathrm{mg}$ and acetazolmide 500mg daily in divided doses. At the same time CSF drainage was done. As vomiting continued, with consultation of endocrinologist and neurologist fundal photgraph (Fig 3) and perimetry were done and she was switched to intravenous dexamethasone $15 \mathrm{mg}$, ondensetrone $24 \mathrm{mg}$ daily in divided doses. In addition lumbar drainage was done. Vomiting subsided and vision also improved significantly as evidenced by follow up fundal photograph (Fig 4) and perimetry after three weeks. She was then switched to oral dexamethasone followed by oral prednisolone. Her follow-up electrolyte showed persistent hyponatraemia which was corrected by addition of fludrocortisone $0.1 \mathrm{mg}$ with prednisolone 7.5mg per day.

\section{Discussion:}

According to her background history of steroid intake, obesity and opthalmoscopic findings, initially we labeled her as a case of iatrogenic Cushing syndrome with raised intracranial pressure (ICP). Her vomiting can be attributable to raised ICP. However, presence of pigmentation was the clinical clue that led us to think an alternative possibility. After biochemical analysis she was found to be a case of Addison's disease and her raised ICP could be attributed to Addison's disease. As very low serum cortisol and very high ACTH were strongly suggestive of diagnosis of Addison's disease, so we did not go for synecthine test. Her long history of irregular low dose steroid intake was responsible for chronicity of illness but was not sufficient for replacement. There are a few reports about the development of raised ICP in Addison's disease ${ }^{2,3}$.
Increased serum and CSF arginine vasopressin peptide (AVP) in a glucocorticoid deficient state is the likely cause of raised ICP in Addison's disease ${ }^{4}$. The mechanism of empty sella in this case is probably due to raised ICP or an autoimmunity which is associated with autoimmune adrenal failure ${ }^{5}$. Our main concern was cortisol replacement and to halt the progression of visual loss. During management with the physiological replacement dose of corticosteroid her hyponatraemia was persistent, which was corrected by addition of fludrocortisone. As her vision was improved by acetazolamide and lumbar drainage we did not go for our initial plan of lumbo peritoneal shunt.

$\mathrm{IIH}$ is defined as the clinical syndrome of raised intracranial pressure in the absence of the space occupying lesion or vascular lesion, without the enlargement of cerebral ventricles for which no causative factor can be identified ${ }^{6}$. Historically IIH was referred to as pseudotumor cerebri as it mimics an intracranial tumor. More recently it has been referred to as benign intracranial hypertension (BIH). This term has also been abandoned because a small but significant number of patients develop visual impairment or visual loss, as in our case. However, even the current term IIH is inaccurate because this condition frequently associated with obesity or with the use of medication including various antibiotics (tetracyclines, nitrofurantoin and nalidexic acid), amiodarone, cyclosporin, both systemic steroids use and withdrawal ${ }^{1}$ and oral contraceptive pill. Moreover various endocrine disorders have also rarely been reported in association with IIH, including Cushing syndrome ${ }^{7}$ hyperthyroidism ${ }^{8}$ as well as administration of thyroxin or growth hormone ${ }^{9}$. There are very few reported cases of IIH associated with Addison's disease in adult ${ }^{1,2}$. Our case is an addition to the world literature of such a rare association.

Although the pathophysiology of IIH is uncertain the mechanisms that have been proposed for its development include increased production of CSF, reduced CSF absorption or increase cerebral venous pressure causing a secondary increase in CSF pressure. Analysis of the CSF arginine vasopresssin peptide (AVP) in the patient with IIH demonstrate it to be elevated compared to healthy controls ${ }^{4}$ This reveals that patient with glucocorticoid deficiency have increased 
plasma level of AVP and a sustained hypersecretion of AVP despite plasma dilution ${ }^{10}$. Thus it is possible that increased serum and possibly CSF AVP may mediate IIH in Addison's disease.

It is to be mentioned here that we were unable to measure serum or CSF AVP to provide the mechanistic link amongst Addison's disease, ICP and AVP. We also failed to rule out the role of autoimmunity in Addison's disease and empty sella. Finally, we could not establish raised ICP purely due to Addison's disease or steroid or combination of both.

\section{References}

1. Manji H, Connolly S, Dorwand N, Kitchen N, Mehta A \& Wills A. Oxford Handbook of Neurology, $2^{\text {nd }}$ edition, 2009, Oxford University Press India, page 166-169

2. Condulis N, Germain G, Charest N, Levy S, Carpenter TO: Pseudotumor cerebri: a presenting manifestation of Addison's disease. Clin Pediatr (Phila) 1997; 36:711-713.

3. Sharma D, Mukherjee R, Moore P, Cuthbertson DJ. Addison's disease presenting with idiopathic intracranial hypertension in 24-year-old woman: a caser report. J Medical Case Reports 2010, 4:60
4. Seckl J and Lightman S. Cerebrospinal fluid neurohypophysial peptides in benign intracranial hypertension. J Neurol Neurosurg Psychiatry 1988; 51(12):1538-1541.

5. Silverio-Fernando KK, Lanition-Ang FL \& Jimeno CA. Primary empty sella with partial hypopituitarism and autoimmune thyroiditis. Phil J Internal Medicine, 2009, 47:83-87.

6. Friedman DI, Jacobson DM. Diagnostic criteria for idiopathic intracranial hypertension. Neurology 2002; 59:1492-1495.

7. Newman PK, Snow M, Hudgson P. Benign intracranial hypertension and Cushing's disease. BMJ 1980; 281:113.

8. Dickman MS, Somasundaram M, Brzozowski L. Pseudotumor cerebri and hyperthyroidism. N Y State J Med 1980; 80:1118-1120.

9. Malozowski S, Tanner LA, Wysowski DK, Fleming GA, Stadel BV. Benign intracranial hypertension in children with growth hormone deficiency treated with growth hormone. J Pediatr 1995; 126(6):996-999.

10. Agus ZS, Goldberg M. Role of antidiuretic hormone in the abnormal water diuresis of anterior hypopituitarism in man. J Clin Invest 1971; 50(7):1478-1489. 